Available online at:

https://ejournal.staindirundeng.ac.id/index.php/bashair/article/view/545

BASHA'IR

Jurnal Studi Alquran dan Tafsir

Published June 2021, 1(1): 1-8

P-ISSN: $x x x x-x x x x$ | E-ISSN: $x x x x-x x x x$

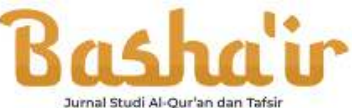

Jurnat Studi at Qur'on dan Tatsir

\title{
SUMBANGAN STUDI ALQURAN BAGI KEILMUAN ISLAM DAN PENDIDIKAN
}

\author{
Muhammad Fikri Abdun Nasir'; Mahmud Arif ${ }^{2}$; \\ ${ }_{1,2}$ UIN Sunan Kalijaga, Yogyakarta \\ 1'fikrimfan27@gmail.com | 2marifnurch@yahoo.co.id
}

\begin{abstract}
Abstrak
Ilmu pengetahuan dan teknologi, khususnya teknologi modern, berubah dengan kecepatan yang sangat cepat, sementara gerakan keagamaan sangat lambat, karena agama dan teknologi tidak selaras. Dalam Encyclopedia of Religions and Philosophy, dijelaskan bahwa Islam adalah agama Allah, dan dia memerintahkan Allah untuk mengajarkan prinsip dan aturan Nabi Muhammad. Dan menugaskannya untuk menyampaikan agama kepada seluruh umat manusia dengan mengajak mereka untuk menerimanya. Salah satu ciri yang membedakan Islam adalah penekanannya pada ilmu pengetahuan. Alquran dan Sunnah mengajak umat Islam untuk mencari dan memperoleh pengetahuan dan kebijaksanaan, dan sangat mementingkan orang yang berilmu. Jika kita perhatikan ayat-ayat dalam Alquran tentang perintah untuk mencari ilmu, maka kita akan menemukan bahwa perintah itu bersifat universal, terutama dalam ilmu yang disebut ilmu agama.Alquran menekankan apakah ilmu itu bermanfaat atau tidak. Kriteria ilmu yang bermanfaat adalah mendekati ilmu Sang Pencipta sebagai bentuk pengabdian kepada-Nya. Perjumpaan antara umat Islam dan dunia modern melahirkan berbagai aliran pemikiran, seperti mazhab Salaf dengan semboyan "Kembali ke Alquran dan Hadits" dan mazhab Tajid dengan semboyan "Maju bersama Alquran". merekomendasikan Reformasi, selama itu tidak mengebiri ajaran Islam yang benar, melainkan memperkuat, mengangkat dan mengangkat martabat umat Islam di hadapan seluruh dunia.
\end{abstract}

\begin{abstract}
Science and technology, especially modern technology, are changing at a very fast pace, while religious movements are very slow, because religion and technology are not in sync. In the Encyclopedia of Religions and Philosophy, it is explained that Islam is the religion of Allah, and he ordered Allah to teach the principles and rules of the Prophet Muhammad. And commissioned him to convey religion to all mankind by inviting them to accept it. One of the distinguishing features of Islam is its emphasis on knowledge. The Qur'an and Sunnah invite Muslims to seek and acquire knowledge and wisdom, and place great importance on those who are knowledgeable. If we look at the verses in the Qur'an about the command to seek knowledge, then we will find that the commandment is universal, especially in the science called religious knowledge. The Qur'an emphasizes whether knowledge is beneficial or not. The criterion of useful knowledge is to approach the knowledge of the Creator as a form of devotion to Him. The encounter between Muslims and the modern world gave birth to various schools of thought, such as the Salaf school with the motto "Back to the Qur'an and Hadith" and the Tajid school with the motto "Forward with the Qur'an". recommends Reformation, as long as it does not castrate the true teachings of Islam, but strengthens, elevates and elevates the dignity of Muslims before the whole world.
\end{abstract}

Keywords: Qur'anic Studies, Islamic Science, Education 


\section{A. PENDAHULUAN}

Alquran adalah sumber utama ajaran Islam. Di dalam Alquran terdapat banyak sekali pelajaran yang dapat diambil. Alquran diturunkan secara berangsur-angsur melalui perantara malaikat Jibril. Keistimewaan Alquran dibandingkan dengan kitab-kitab suci yang lain ialah kemurnian atau keaslian Alquran dijaga langsung oleh Allah, agar tidak ada satupun ayat-Nya yang berubah. Sebagaimana ditegaskan dalam Alquran, Allah SWT berfirman :

"Sesungguhnya Kami-lah yang menurunkan Alquran, dan Kami pula-lah yang menjaganya"

Umat Islam yakni kaum muslim, apapun jenis aliran yang mereka anut dan dimana pun mereka hidup, tentu menjadikan Alquran sebagai pedoman kehidupan religiusnya. Konsekuensinya, Alquran pasti menempati posisi paling sentral dalam kegiatan apapun yang terkait aspek religius setiap muslim, tinggal tergantung pada pemahaman dan pengamalan masing-masing individu muslim tersebut. Namun permasalahannya, sudahkah Alquran dijadikan dasar dan "penerang" dalam memandang, menyikapi, dan menjalankan peran kita, bukan semata untuk kepentingan apa yang kita istilahkan dengan ibadah yang religius, melainkan untuk apa yang kita istilahkan dengan hidup yang realistis.

Dalam pandangan umat Islam, Alquran menjadi sumber dari segala sumber hukum, sehingga segala yang berkaitan dengan aktifitas manusia baik yang bersifat individu maupun kelompok berpijak terhadap Alquran. Namun yang menjadi persoalan apakah Alquran telah menjadi suatu sentral dalam studi islam?

Dari Alquran pula ilmu-ilmu pengetahuan berkembang, baik ilmu pengetahuan umum maupun ilmu pengetahuan agama. Mempelajari Alquran adalah kewajiban. Bagi umat Islam, pengertian kita terhadap hubungan antara Alquran dan ilmu pengetahuan akan memberi pengaruh yang tidak kecil terhadap perkembangan agama dan sejarah perkembangan manusia pada generasigenerasi yang akan datang (M. Shihab, 1992).

Alquran atau sering pula disebut dengan kitabullah merupakan sumber utama ajaran Islam. Alquran adalah wahyu Allah SWTyang paling agung dan sempurna yang dijadikan pedoman umat Islam. Didalamnya terdapat berbagai prinsip dan ajaran dasar Islam meliputi aqidah, syari'ah dan akhlaq. Dalam makalah ini, kami akan membahas tentang posisi Alquran dalam studi keislaman.Berkaitan dengan Alquran dengan studi keislaman, maka substansi yang terdapat dalam pendidikan Islam, secara konsep dasar terdapat dalam Alquran dan Al-Hadits yang mana di dalamnya adalah ajaran normatif (Fatih, 2018). Untuk itu amat penting peran Alquran dalam studi keislaman dewasa ini

\section{B. METODE PENELITIAN}

Studi literatur adalah bagian kegiatan yang berkaitan dengan metode pengumpulan data pustaka, mencatat dan membaca, serta acuan bahan penelitian.

Menurut Danial dan Warsiah Studi Literatur adalah mewujudkan analisis yang dilakukan oleh penjelajah tambah menggerakkan beberapa pustaka, tabloid yang berhubungan tambah bagian dan target analisis. Sedangkan Punaji mengucapkan tilikan wacana mewujudkan setara tilikan atau maksud bab daftar acuan yang relevan tambah mayapada atau wujud terbatas sebagaimana terdapat bagian dalam primbon-primbon ilmiah dan butir jurnal. Ia merelakan tilikan tentang apa yang perasan dibahas atau dibicarakan oleh penjelajah atau penulis, akaid-akaid dan taksiran yang mendukung, komplikasi analisis yang diajukan atau ditanyakan, peraturan dan metodologi yang 
sesuai. Teknik ini dilakukan berharap kepada menuliskan berbagai akaid yang relevan seperti bibit referensi bagian dalam penyelesaian komplikasi yang sedang dihadapi.

Jenis penelitian yang digunakan dalam artikel adalah kajian kepustakaan (literature review). Data yang digunakan dalam penelitian ini berupa data-data dokumen, baik dari buku teks, jurnal ilmiah, serta sumber-sumber dokumen lain yang relevan. Setelah data dikumpulkan maka dilakukan analisis kritis sehingga dapat disajikan secara deskriptif guna mendapatkan rumusan kesimpulan yang tepat dan akurat.

\section{HASIL DAN PEMBAHASAN}

\section{Kontribusi Studi Alquran bagi Islam}

Alquran adalah merupakan sumber ajaran Islam karena Alquran langsung diturunkun oleh Allah SWT melalui Malaikat Jibril kepada Nabi Muhammad untuk menjadi petunjuk bagi seluruh umat manusia baik yang beragama Islam maupun yang tidak beragama Islam. Karena Alquran merupakan pokok ajaran Islam, maka segala studi mengenai keislaman tidak boleh bertentangan dengan sumber pokok ini.

Apabila kita perhatikan, maka susunan Alquran adalah merupakan suatu susunan yang tidak tertandingi, sehingga dari segi ini dapat dipahami berbagai kemungkinan pengertian, karena kalimat-kalimatnya simpel dan isinya padat. Berdasarkan janji Allah SWT., bahwa kalimat-kalimat Alquran yang terlihat sederhana bila direnungkan berulang-ulang dan secara mendalam, baik dari segi bahasanya maupun dari segi kandungannya merupakan suatu sumber pengetahuan yang tidak akan selesai-selesainya untuk dibahas. (Hasan, 2000)

Janji Allah tersebut sebagaimana firman-Nya:

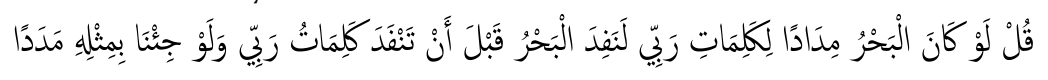

Katakanlah (Muhammad), "Seandainya lautan menjadi tinta untuk (menulis) kalimat-kalimat Tuhanku, maka pasti habislah lautan itu sebelum selesai (penulisan) kalimat-kalimat Tuhan-ku, meskipun kami datangkan tambahan sebanyak itu (pula)". (Al-Kahfi : 109)

Ayat tersebut menyatakan bahwa Alquran adalah merupakan sumber segala ilmu pengetahuan yang tidak pernah kering bila dibahas, khususnya mengenai keislaman. Jadi isi Alquran meliputi segala macam persoalan, dan bisa dibahas dari berbagai aspek. Alquran juga dapat dilihat dari segi kandungannya yang bukan hanya mengemukakan persoalan-persoalan yang menyangkut peribadatan saja, tetapi meliputi juga persoalan teologi, persoalan kemasyarakatan, persoalan eksistensi manusia bahkan persoalan-persoalan yang menyangkut pemenuhan kebutuhan hidup manusia seperti ilmu dan teknologi. Karena posisi Alquran sebagai sumber ajaran Islam yang pertama, maka segala sesuatu pembahasan mengenai keIslaman, baik yang menyangkut ajaran maupun yang menyangkut unsur-unsur pendukung terlaksananya ajaran tersebut, seluruhnya mengacu kepada Alquran. Bagi orang-orang yang percaya akan kemu'jizatan Alquran, maka Alquran itu betul-betul akan menjadi petunjuk baginya dalam kehidupan beragama, bermasyarakat dan bernegara (Hasan, 2000).

Alquran mengandung pengertian yang lengkap mengenai segala aspek kehidupan manusia, alam semesta dan metafisika, masa lampau, masa kini dan masa depan, individu, masyarakat, sosial politik, dan sebagainya.

Dilihat dari abad ke abad, umat Islam tidak pernah berhenti mengembangkan ilmu pengetahuan di mana saja mereka berada. Pada negeri-negeri yang diilhami oleh umat Islam selalu 
terdapat lembaga tempat perkembangan ilmu pengetahuan terutama ilmu bersumber dari Alquran. Dalam lembaga-lembaga ini diajarkan tentang Alquran dan tafsirnya, hadits, ilmu fikih, teologi Islam, mantiq, astronomi, sejarah dan lain-lain. Kalau kita kaji lebih mendalam isi Alquran yang menginformasikan berbagai aspek kehidupan, seperti aspek keagamaan, politik, ekonomi, sosial budaya dan aspek-aspek lainnya, sungguh betapa lengkapnya Alquran sebagai sumber ajaran Islam (Abuddin Nata : 2013).

Tidak ada satu pun yang terlupakan atau tertinggal dalam ayat-ayat Alquran yang membahas tentang segala aspek kehidupan manusia. Alquran dalam menginformasikan berita dari Allah tidak terlepas dari unsur nalar dan berbagai aspek lainnya, agar informasi tersebut dapat dipahami dan diterima oleh obyeknya.

Dalam perkembangan Islam, aspek nalar memainkan peranan penting. Dalam membahas bidang-bidang keagamaan, ulama-ulama Islam tidak semata-mata berpegang pada wahyu, tetapi banyak pula berpegang pada akal. Peranan akal besar sekali dalam pembahasan masalah-masalah keagamaan yang kita jumpai, bukan hanya dalam bidang Filsafat, tetapi juga dalam bidang tauhid, bahkan dalam bidang fikih dan tafsir, karena Allah sendiri memerintahkan hamba-Nya berpikir. Alquran sebagai sumber ajaran Islam tidak dapat direalisasikan dalam kehidupan masyarakat, kalau isi serta kandungannya itu belum dapat dipahami dengan baik, karena isi dan kandungan Alquran itu harus dilaksanakan dalam kehidupan sehari-hari.

Memahami Alquran tidaklah mudah, karena kita harus mengetahui sebab turunnya, lebihlebih dalam memahami ayat-ayat mutasyabihat dan pengetahuan lainnya. Dengan demikian dirasakan kebutuhan mengembangkan beberapa peralatan ilmiah untuk mengontrol kemajuan ilmu yang berhubungan dengan Alquran (ilmu tafsir). Karena itu pertama-tama menjadi prinsip adalah, bahwa tidak hanya pengetahuan mengenai hahasa Arab saja yang diperlukan untuk memahami Alquran secara tepat, tetapi juga ilmu-ilmu yang lain seperti idiom-idiom bahasa Arab pada zaman Nabi. Dari sini berkembanglah gramatika bahasa Arab, ilmu perkamusan dan kesusastraan Arab dengan suburnya.

Selanjutnya latar belakang turunnya ayat-ayat Alquran yang disebut "asbab al nuzul" dijadikan sebagai alat yang perlu untuk menerapkan makna yang tepat dari firman Allah. Di samping itu perlu juga diketahui dan dianggap sangat penting bagaimana caranya orang-orang di lingkungan Nabi memahami perintah-perintah Alquran. Setelah persyaratan-persyaratan ini dipenuhi, barulah penggunaan nalar manusia diberi tempat. Untuk itu bermunculanlah kitab-kitab tafsir sehingga pandangan apa pun yang ingin diproyeksikan dan dibela oleh kaum Muslimin, mengambil bentuk dalam berbagai tafsir Alquran.

Dalam pandangan al Qur'an, ilmu adalah keistimewaan yang menjadikan manusia unggul dibandingkan dengan makhluk-makhluk lainnya yang sama-sama diciptakan oleh Allah Swt, karena manusia diciptakan oleh Allah adalah untuk menjadi khalifah Allah di muka bumi, maka tangggung jawab manusia di muka sangatlah berat, karena harus mempertanggungjawabkan segala sesuatu amal perbuatan, baik yang ma'ruf maupun yang mungkar, oleh karenanya manusia hidup di dunia itu harus mempunyai sejumlah ilmu pengetahuan, sehingga punya kemampuan untuk mempertanggungjawabkan di hadapan Allah.Untuk mendapatkan ilmu terlebih dahulu harus mengetahui dari mana sumber ilmu itu, untuk apa ilmu itu dipelajari, sehingga apa apa yang dicari benar-benar dapat memberi manfaat yang sangat luas bagi kemaslahan umat manusia (Masduki, 2016). 
Alquran sebagai sumber berbagai disiplin ilmu keislaman Islam bukan hanya terdiri dari satu dua aspek saja, tetapi memiliki beberapa aspek, yaitu aspek teologi, ibadah, akhlaq, filsafat, kebudayaan, dan lain sebagainya. Semua aspek itu dtulis dan dibahas oleh para ahli sehingga melahirkan berbagai ilmu yang kemudian dikenal dengan ilmu-ilmu keislaman (Nasiri, 2019).

\section{Kontribusi Studi Alquran bagi Pendidikan}

Berbicara mengenai Alquran dengan pendidikan tidak bisa dipisahkan dari pembicaraan mengenai kedudukan Alquran bagi pendidikan. Dalam buku berjudul "Islamic Education Qur'anic Out-look”, Abdur Rahman Saleh menyimpulkan bahwa Alquran adalah kitab pendidikan yang didasar kanpada alasan-alasan sebagai berikut (Atiqah Azizah : 2018)

a. Dilihat dari segi surat yang pertama kali diturunkan adalah surat yang berkaitan dengan pendidikan.

b. Dilihat dari segi asalnya bahwa Alquran berasal dari Allah yang beberapa sifatnya Ia memperkenalkan dirinya sebagai pendidik.

c. Dilihat dari segi pembawanya yaitu Nabi Muhammad saw., juga telah tampil sebagai pendidik.

d. Dilihat dari segi namanya terdapat sejumlah nama Alquran yang terkait dengan pendidikan.

e. Dilihat dari misi utamanya Alquran membawa misi utama tentang pembinaan akhlak mulia.

Berbicara tentang Alquran sesungguhnya adalah juga berbicara tentang pendidikan yang justrulebih utuh dan mendasar. Jika pendidikian dimaksudkan adalah untuk membawa anak manusia menjadi lebih sempurna yang dilakukan secara terus menerus dan tidak mengenal henti, maka Alquran sesungguhnya diturunkan ke bumi melalui Muhammad saw, dimaksudkan memberikan petunjuk, penjelasan, rahmat, pembeda dan obat bagi manusia agar tidak tersesat dalam hidupnya.

Seluruh isi Alquran berbicara tentang pendidikan, surat al-Fatihah misalnya yang disebut sebagai induk Alquran memberikan tuntutan hidup menyeluruh sekalipun secara garis besar, mengajarkan tentang kasih sayang, bersyukur, tidak saja di dunia tetapi juga sampai di akherat.

Jika Rasulullah saw diutus ke bumi adalah untuk melakukan bimbingan kehidupan umat manusia ke jalan yang benar, agar mereka selamat di dunia dan akhirat, maka Nabi Muhammad saw juga merupakan sosok pendidik yang sempurna yang tidak ada seorangpun yang menyamai kualitasnya. Meskipun Nabi Muhammad saw sebagai seorang ummi, tidak pintar membaca dan menulis, dia tidak sanggup menjadi guru membaca, akan tetapi dia mampu menjadi pendidik secara sempurna. Dia mendorong umatnya untuk belajar membaca dan bahkan mencari jalan keluar bagaimana caramembaca itu dengan menugasi para tawanan perang mengajari membaca menulis sebagai syarat dibebaskan sebagai tawanan perang.

Sebagai kalam Allah yang diwahyukan kepada Nabi Muhammad saw. Alqur'an menjadi sumber pendidikan Islam pertama dan utama. Alquran merupakan petunjuk yang lengkap, pedoman bagi manusia yang meliputi seluruh aspek kehidupan manusia dan bersifat unversal (Ramayulis, 1994). Keuniversalan ajarannya mencakup ilmu pengetahuan yang tinggi dan sekaligus merupakan kalam mulia yang esensinya tidak dapat dimengerti, kecuali bagi orang yang berjiwa suci dan berakal cerdas. Alquran diturunkan Allah untuk menunjuki manusia ke arah yang lebih baik. Firman Allah swt surah An-Nahl Ayat 64 :

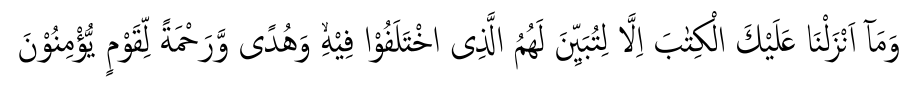


"Dan Kami tidak menurunkan kepadamu al-Kitab (Alquran) melainkan agar kamu dapat menjelaskan kepada mereka apa yang mereka perseliisihkan itu dan menjadi petunjuk dan rahmat bagi kaum beriman"

Alquran menduduki tempat paling depan dalam pengambilan sumber-sumber pendidikan lainnya. Segala kegiatan dan proses pendidikan Islam haruslah senantiasa berorientasi kepada prinsip dan nilai-nilai Alquran. Di dalam Alquran terdapat beberapa hal yang sangat positif guna pengembangan pendidikan. Hal-hal itu antara lain, penghormatan kepada akal manusia, bimbingan ilmiah, tidak menentang fitrah manusia, serta memelihara kebutuhan sosial.

Alquran memiliki perbendaharaan luas dan besar bagi pengembangan kebudayaan umat manusia. Ia merupakan sumber pendidikan yang terlengkap, baik itu pendidikan sosial, moral, spritual, material serta alam semesta. Alquran merupakan sumber nilai yang absolut dan utuh. Eksistensinya tidak akan pernah mengalami perubahan. Kemungkinan terjadi perubahan hanya sebatas interpretasi manusia terhadap teks ayat yang menghendaki kedinamisan pemaknaannya, sesuai dengan konteks zaman, situasi, kondisi, dan kemampuan manusia dalam melakukan interpretasi. Ini merupakan pedoman normatif-teoritis bagi pelaksanaan pendidikan Islam yang memerlukan penafsiran lebih lanjut.

Isinya mencakup seluruh dimensi manusia dan mampu menyentuh seluruh potensi manusia, baik itu motivasi untuk mempergunakan pancaindera dalam menafsirkan alam semesta bagi kepentingan formulasi lanjut pendidikan manusia (pendidikan Islam), motivasi agar manusia mempergunakan akalnya, lewat perumpamaan-perumpamaan (tamsil) Allah SWT dalam Alquran, maupun motivasi agar manusia mempergunakan hatinya untuk mampu mentransfer nilai-nilai pendidikan Ilahiah dan sebagainya. Kesemua proses ini merupakan sistem umum pendidikan yang ditawarkan Allah Swt. dalam Alquran agar manusia dapat menarik kesimpulan dan melaksanakan kesemua petunjuk tersebut dalam kehidupannya sebaik mungkin. Menurut Abdurrahman Saleh, karena Alquran memberikan pandangan yang mengacu kehidupan di dunia ini, maka asas-asas dasarnya harus memberi petunjuk kepada pendidikan Islam. Seseorang tidak mungkin dapat berbicara tentang pendidikan Islam bila tanpa mengambil Alquran sebagai satu-satunya rujukan (Saleh, 1994).

Oleh karena itu, pelaksanaan pendidikan Islam harus senantiasa mengacu pada sumber yang termuat dalam Alquran. Dengan berpegang kepada nilai-nilai yang terkandung dalam Alquran terutama dalam pelaksanaan pendidikan Islam, akan mampu mengarahkan dan mengantarkan manusia bersifat dinamis-kreatif serta mampu mencapai esensi nilai-nilai ubudiyah pada Penciptanya. Dengan sikap ini, maka proses pendidikan Islam akan senantiasa terarah dan mampu menciptakan dan mengantarkan outputnya sebagai manusia berkualitas dan bertanggungjawab terhadap semua aktivitas yang dilakukannya. Hal ini dapt dilihat bahwa hampir dua pertiga dari ayat Alquran mengandung nilai-nilai yang membudayakan manusia dan memotivasi manusia untuk mengembangkannya lewat proses pendidikan.

Dari sini, Alquran memiliki misi dan implikasi kependidikan yang bergaya imperatif, motivatif, dan persuasive-dinamis, sebagai suatu sistem pendidikan yang utuh dan demokrasi lewat proses manusiawi. Proses kependidikan tersebut bertumpu pada kemampuan rohaniah dan jasmaniah masing-masing individu peserta didik, secara bertahap dan berkesinambungan, tanpa melupakan kepentingan perkembangan zaman dan nilai-nilai Ilahiah. Kesemua proses kependidikan Islam tersebut merupakan proses konservasi dan transformasi, scrta internalisasi nilai-nilai dalam 
kehidupan manusia sebagaimana yang diinginkan oleh ajaran Islam. Dengan upaya ini, diharapkan peserta didik mampu hidup secara serasi dan scimbang, baik dalam kehidupan di dunia maupun di akhirat.

\section{KESIMPULAN}

Kesimpulan yang dapat diambil dari makalah ini adalah bahwa Alquran menempati posisi sentral bukan saja dalam perkembangan dan pengembangan ilmu-ilmu keislaman, tetapi juga merupakan inspirator dan pemandu gerakan- gerakan umat Islam sepanjang zaman.

Alquran adalah sumber berbagai ilmu keislaman. Karena Alquran merupakan pokok ajaran Islam, maka segala studi mengenai keislaman tidak boleh bertentangan dengan sumber pokok ini. Bersumber dari Alquran dan Hadis banyak berkembang berkembang ilmu pengetahuan seperti, ilmu tasawuf, teologi, filsafat, fiqh,dan lain-lain.

Alquran menduduki tempat paling depan dalam pengambilan sumber-sumber pendidikan. Segala kegiatan dan proses pendidikan Islam haruslah senantiasa berorientasi kepada prinsip dan nilai-nilai Alquran. Di dalam Alquran terdapat beberapa hal yang sangat positif guna pengembangan pendidikan

Setelah kita memahami kadudukan Alquran tersebut secara utuh maka kita dapat menjadikan Alquran sesuatu yang sangat berperan secara langsung bagi keberlangsungan kehiduapan ummat manusia di permukaan bumi ini, karna tanpa adanya Alquran tersebut maka peradapan manusia saat ini akan kacau, tidak ada rasa hormat antara manusia, tidak terjalinnya silaturahim antara muslim, keadaan kehidupan manusia semrawut, terjadinya penghardian terhadap anak yatim dan sebagainya.

\section{DAFTAR PUSTAKA}

Atiqah, A. (t.thn.). Konsep Tarbiyah dalam Alquran. Analytica Islamica, 7(1).

Danial, E. d. (2009). Metode Penulisan Karya Ilmiah. Bandung: Laboratorium Pkn UP.

Departemen Agama RI. (2005). Alquran dan Terjemahnya. Bandung: Diponogoro.

Fatih, M. R. (2018). Model Kepemimpinan dan PengembanganPotensi Pemimpin Pendidikan Islam. Cendekia: Jurnal Studi Keislaman, 4(2).

Hasan, A. M. (2000). Studi Islam, Alquran dan As Sunnah. Jakarta: PT Raja Grafindo Persada. Jakarta: PT. Raja Grafindo Persada.

M. Shihab, Q. (1992). Membumikan Alquran. Bandung: Mizan.

Masduki, Y. (2016). Kontribusi Keilmuan Alquran Bagi Umat Islam. Medina-Te, Jurnal Studi Islam, 14(2).

Nasiri. (2019). Posisi Alquran Dalam Studi Keislaman. Tasyri', 26(1).

Ramayulis. (1994). Ilmu Pendidikan Islam. Jakarta: Kalam Mulia.

Saleh, A. A. (1994). Teori-teori Pendidikan Berdasarkan Alquran, terj. H. M. Arifim dan Zainuddin. Jakarta: PT. Rineka Cipta. Jakarta: PT. Rineka Cipta. 